\title{
Statistical evaluation of the medium components for the production of high biomass, $\alpha$-amylase and protease enzymes by Piriformospora indica using Plackett-Burman experimental design
}

\author{
S. Swetha $\cdot$ Ajit Varma $\cdot$ T. Padmavathi
}

Received: 8 April 2013/Accepted: 26 August 2013/Published online: 6 September 2013

(C) The Author(s) 2013. This article is published with open access at Springerlink.com

\begin{abstract}
Piriformospora indica, a member of basidiomycota is an axenically cultivable endophytic fungus which exerts plant growth promoting effects on its host plant. $P$. indica is known to produce $\alpha$-amylase and protease. Since the organism exhibits beneficial role in plant growth promotion, achieving high biomass is immensely essential. Hence to enable the commercial production, screening of medium components is a necessary step. The present paper investigates the screening of medium components using Plackett-Burman experimental design wherein the parameters such as $\alpha$-amylase, protease and biomass have been examined. The parameters $\alpha$-amylase, protease and biomass was found to vary from 0.25 to $0.45 \mathrm{mg}^{-1} \mathrm{ml}^{-1} \min ^{-1}, 0.1$ to $0.15 \mathrm{mg}^{-1} \mathrm{ml}^{-1} \mathrm{~h}^{-1}$ and 0.8 to $22.6 \mathrm{~g} \mathrm{l}^{-1}$, respectively, in 16 runs which demonstrates the strong influence of the medium components.
\end{abstract}

Keywords Piriformospora indica $\cdot$ Submerged fermentation · Plackett-Burman experimental design . $\alpha$-Amylase $\cdot$ Protease

\section{Introduction}

Piriformospora indica is an axenically cultivable, facultative root endophytic fungus belonging to basidiomycota possessing simple dolipore septum with continuous and

S. Swetha $\cdot$ T. Padmavathi $(\bowtie)$

Department of Microbiology, Centre of PG Studies, Jain University, 9th Main, Jayanagar 3rd Block, Bangalore, India e-mail: vam2010tpraviju@gmail.com

A. Varma

Amity Institute of Herbal and Microbial Studies, Sector 125, Noida 201303, UP, India straight parenthosomes. It was isolated from the rhizosphere of the woody shrubs Prosopsis juliflora and Zizyphus nummularia growing in Indian Thar desert (Varma et al. 1998). P. indica enhances the growth and yield of plants, protects against biotic (resistance against pathogens) and abiotic stress (salt stress) (Rai et al. 2001, Waller et al. 2008) by colonizing a broad spectrum of mono and dicotyledenous plants. It also produces a large number of thick walled, pear shaped chlamydospores having longer shelf life. The sporulating nature of this fungus has made it competent enough for exploiting it for commercial application (Kumar et al. 2011).

Microbial enzymes find increasing industrial applications; among them amylases and proteases occupy large share of the total enzyme market. $\alpha$-Amylases and proteases have wide applications in starch processing, brewing, alcohol production, dairy industries, and textile industries, pharmaceutical and detergent industries, respectively (Sumrin et al. 2011; Saxena and Singh 2010).

The cell growth, spore production and accumulation of metabolic products are strongly influenced by the medium components such as carbon sources, nitrogen sources, various inorganic salts and trace elements. Screening of medium components and their optimization is therefore an important criterion for large-scale production. Classical method, factorial combination of medium optimization involving one variable at a time by keeping others at fixed level fails as it is laborious, time consuming; moreover, it does not guarantee the optimal conditions. Hence statistical approach such as Plackett-Burman design (provide statistical model) is a useful tool for the screening of nutrients as it helps in determining the significant impact on growth rate, which in turn aids in understanding the interactions among the process parameters at different levels (Rajendran et al. 2007). The use of statistical experimental design 
in medium optimization has gained considerable attention in recent years and also number of publications describing the application of these methods for the production of various enzymes and biomolecules has appeared in the literature (Seraman et al. 2010). However, there seems to be no reports available for the production of $\alpha$-amylases and proteases by $P$. indica. The present paper demonstrates the screening of the important medium components affecting the large-scale cultivation of $P$. indica and also the production of $\alpha$-amylase and protease enzymes by $P$. indica, which has tremendous applications in the field of plant biotechnology as a biological hardening tool, biofertilizer and biocontrol agent.

\section{Materials and methods}

Microorganism and culture maintenance

The culture of $P$. indica with an accession number of AF014929 USA was obtained from Prof. Ajit Varma (Amity Institute of Herbal and Microbial Studies, Noida, India). The stock culture was maintained on potato dextrose agar at optimum conditions and stored at $4{ }^{\circ} \mathrm{C}$ for further studies.

\section{Screening of medium components}

A total of 12 variables including different carbon, nitrogen sources, trace element solution [zinc sulphate $\left(\mathrm{ZnSO}_{4} \cdot 7 \mathrm{H}_{2} \mathrm{O}\right)$, boric acid $\left(\mathrm{H}_{3} \mathrm{BO}_{3}\right)$, manganous chloride $\left(\mathrm{MnCl}_{2}\right)$, cobaltous chloride $\left(\mathrm{CoCl}_{2}\right)$, copper sulphate $\left(\mathrm{CuSO}_{4}\right)$ and ammonium molybdate $\left(\left(\mathrm{NH}_{4}\right)_{6} \mathrm{Mo}_{7} \mathrm{O}_{24} \cdot 4 \mathrm{H}_{2} \mathrm{O}\right)$ and $20 \times$ salt solution [sodium nitrate $\left(\mathrm{NaNO}_{3}\right)$, potassium chloride, magnesium sulphate $\left(\mathrm{MgSO}_{4} \cdot 7 \mathrm{H}_{2} \mathrm{O}\right)$ and potassium di hydrogen phosphate $\left.\left(\mathrm{KH}_{2} \mathrm{PO}_{4}\right)\right]$ at different levels as per the statistical model were used along with potato dextrose media for screening (Table 1).

\section{Submerged fermentation}

$1 \times 10^{-6} \mathrm{ml}^{-1}$ of the culture was inoculated to all the flasks (16 runs) designed as per the statistical experimental design and these flasks were incubated at $30{ }^{\circ} \mathrm{C}$ under continuous shaking conditions $(120 \mathrm{rpm})$ and the response was measured in terms of biomass, amylase and protease production.

Measurement of cell growth

The culture broth was filtered through pre-weighed Whatman No. 1 filter paper, dried in a hot air oven at $60{ }^{\circ} \mathrm{C}$ for
48-72 $\mathrm{h}$ and the growth of $P$. indica was expressed in terms of dry cell weight per liter of the culture broth.

$\alpha$-Amylase activity

$\alpha$-Amylase activity was performed using $1 \%$ soluble starch as substrate (optimum condition) followed by the estimation of reducing sugars using dinitrosalicylic acid (Miller 1959). One unit of amylase activity was defined as the amount of enzyme that liberates reducing sugar equivalent to $1.0 \mathrm{mg}$ glucose under specific assay conditions.

Protease activity

Protease activity using casein as substrate was performed according to Rodarte et al. (2011) with some modifications. The reaction mixture containing cell-free extract, $0.5 \%$ casein along with citrate buffer of $\mathrm{pH} 5$ was incubated for $4 \mathrm{~h}$ at room temperature followed by the addition of $5 \%$ trichloroacetic acid and centrifuged at 8,000 rpm for $10 \mathrm{~min}$. The supernatant was further analyzed by Lowry's method (Lowry et al 1951). One unit of the protease activity was defined as the amount of enzyme required to liberate $1 \mu \mathrm{g}$ of tyrosine per hour under the experimental conditions.

\section{Plackett-Burman design}

The Plackett-Burman design based on the first order model was used to screen and evaluate the important medium components that influence the production of $\alpha$-amylase and protease. All the experiments were carried out according to designed matrix using the equation $Y=\beta_{o}+\sum \beta_{i} X_{i}(i=$ $l . . k$ ), where $Y$ is the estimated target function (yield of $\alpha$ amylase/protease/biomass), $\beta_{o}$ is a model intercept, $\beta_{i}$ is the regression coefficient. $X$ is the independent variable and $k$ is the number of variables (Rajendran et al. 2007; Seraman et al. 2010). The Student's $t$ test was performed to determine the significance of each variable employed. The regression coefficient was determined by least square method.

\section{Results}

The coefficient and the $p$ values of the factors were studied using the statistical software MATLAB. $\alpha$-Amylase activity, protease activity and biomass were found to vary from 0.2555 to $0.4554 \mathrm{mg}^{-1} \mathrm{ml}^{-1} \mathrm{~min}^{-1}, 0.1$ to $0.158 \mathrm{mg}^{-1}$ $\mathrm{ml}^{-1} \mathrm{~h}^{-1}$ and 0.8 to $22.6 \mathrm{~g} \mathrm{l}^{-1}$, respectively, in 16 runs which shows the strong influence of the medium components. The variables were classified into positive and 
Table 1 Plackett-Burman experimental design for the evaluation of 12 variables for $\alpha$-amylase, protease and biomass

\begin{tabular}{|c|c|c|c|c|c|c|c|c|c|c|c|c|}
\hline Run & $\begin{array}{l}\text { Soluble } \\
\text { starch }\end{array}$ & Maltose & Sucrose & Glycerol & $\begin{array}{l}\text { Carboxy methyl } \\
\text { cellulose }\end{array}$ & $\begin{array}{l}\text { Sodium } \\
\text { nitrate }\end{array}$ & $\begin{array}{l}\text { Ammonium } \\
\text { chloride }\end{array}$ & $\begin{array}{l}\text { Malt } \\
\text { extract }\end{array}$ & Peptone & $\begin{array}{l}\text { Yeast } \\
\text { extract }\end{array}$ & $\begin{array}{l}\mathrm{TE} \\
\text { solution }\end{array}$ & $\begin{array}{l}20 \times \text { salt } \\
\text { solution }\end{array}$ \\
\hline 1 & + & + & - & + & - & + & + & - & + & - & + & + \\
\hline 2 & + & + & + & - & + & + & - & + & - & - & + & - \\
\hline 3 & + & - & + & - & - & + & + & - & + & + & - & - \\
\hline 4 & + & + & - & + & - & - & - & + & + & - & - & - \\
\hline 5 & + & - & - & - & - & + & + & + & - & - & + & + \\
\hline 6 & + & + & + & - & + & - & + & - & - & - & - & + \\
\hline 7 & - & + & - & - & + & + & - & - & + & + & - & + \\
\hline 8 & + & - & - & + & + & + & - & + & - & + & - & + \\
\hline 9 & + & - & - & + & + & - & + & - & - & + & + & - \\
\hline 10 & - & + & + & + & - & - & - & - & - & + & + & + \\
\hline 11 & - & - & + & + & + & + & - & - & + & - & + & - \\
\hline 12 & + & - & + & - & - & - & - & + & + & + & + & + \\
\hline 13 & - & - & + & + & + & - & + & + & + & - & - & + \\
\hline 14 & - & + & - & - & + & - & + & + & + & + & + & - \\
\hline 15 & - & + & + & + & - & + & + & + & - & + & - & - \\
\hline 16 & - & - & - & - & - & - & - & - & - & - & - & - \\
\hline
\end{tabular}

+ higher level $(0.1 \mathrm{~g}),-$ lower level $(0.05 \mathrm{~g})$

negative variables based on their main effect which in turn highlights the direction of optimization. More than half of the considered parameters were significantly acting on the system. The components such as starch, glycerol, maltose, TE solution and salt solution have positive effect, whereas sodium nitrate and ammonium chloride has a negative effect on the above-mentioned activities.

Pareto plots give a clear view about the role of each variable (Fig. 1a-c). Soluble starch, maltose, sucrose, TE solution and glycerol had a positive effect on $\alpha$-amylase activity where as sodium nitrate, ammonium chloride, yeast extract, malt extract, carboxymethyl cellulose and salt solution had negative effect as shown in Fig. 1a. Figure 1b depicts the pareto plot of protease activity which reveals that maltose, malt extract, TE solution, glycerol, yeast extract and salt solution had a positive effect, whereas the soluble starch, sodium nitrate, ammonium chloride, peptone, sucrose, carboxymethyl cellulose had a negative effect. Soluble starch, maltose, ammonium chloride, malt extract, peptone, TE solution, yeast extract and salt solution supported in enhancing the biomass but sodium nitrate, sucrose, glycerol and carboxymethyl cellulose depicted negative role in the enhancement of growth of $P$. indica (Fig. 1c).

Total terms in the quadratic equation were 91 including 1 constant, 66 interactions, 12 linear and 12 pure quadratic terms.

To obtain the relevant parameter, the constant term and the linear effect alone were taken into consideration, and the following formula was used.
$C 1+C 2 \times$ soluble starch $+C 3 \times$ sodium nitrate $+C 4$

$\times$ maltose $+C 5 \times$ ammonium chloride

$+C 6 \times$ malt extract $+C 7 \times$ peptone $+C 8 \times$ sucrose

$+C 9 \times \mathrm{TE}$ solution $+C 10 \times$ glycerol

$+C 11 \times$ yeast extract $+C 12 \times \mathrm{CMC}+C 13$

$\times$ salt solution.

$\alpha$-Amylase activity

The linear effect of soluble starch, ammonium chloride and TE solution were found to be more significant than other variables for the production of $\alpha$-amylase enzyme by $P$. indica as given in Table 2. Figure 2 represents the response surface plots of the effect of various combinations of independent variables such as (1) ammonium chloride and soluble starch, (2) glycerol and TE solution for the production of $\alpha$-amylase. The interactions of ammonium chloride and soluble starch on $\alpha$-amylase production was significant as shown in Fig. 2a. Activity increased with increase in concentration of soluble starch, whereas the effect was opposite for ammonium chloride as depicted in Table 2. The maximum value observed was $0.43 \mathrm{mg}^{-1} \mathrm{ml}^{-1} \mathrm{~min}^{-1}$ at $0.05 \%(\mathrm{w} / \mathrm{v})$ of ammonium chloride and $0.1 \%(\mathrm{w} / \mathrm{v})$ of soluble starch. Similarly in case of glycerol and TE solution, the maximum value observed was $0.42 \mathrm{mg}^{-1} \mathrm{ml}^{-1} \mathrm{~min}^{-1}$ at $0.1 \%$ (w/v) of glycerol and TE solution as the effect of both the variables were positive and dominating (Fig. 2b). 

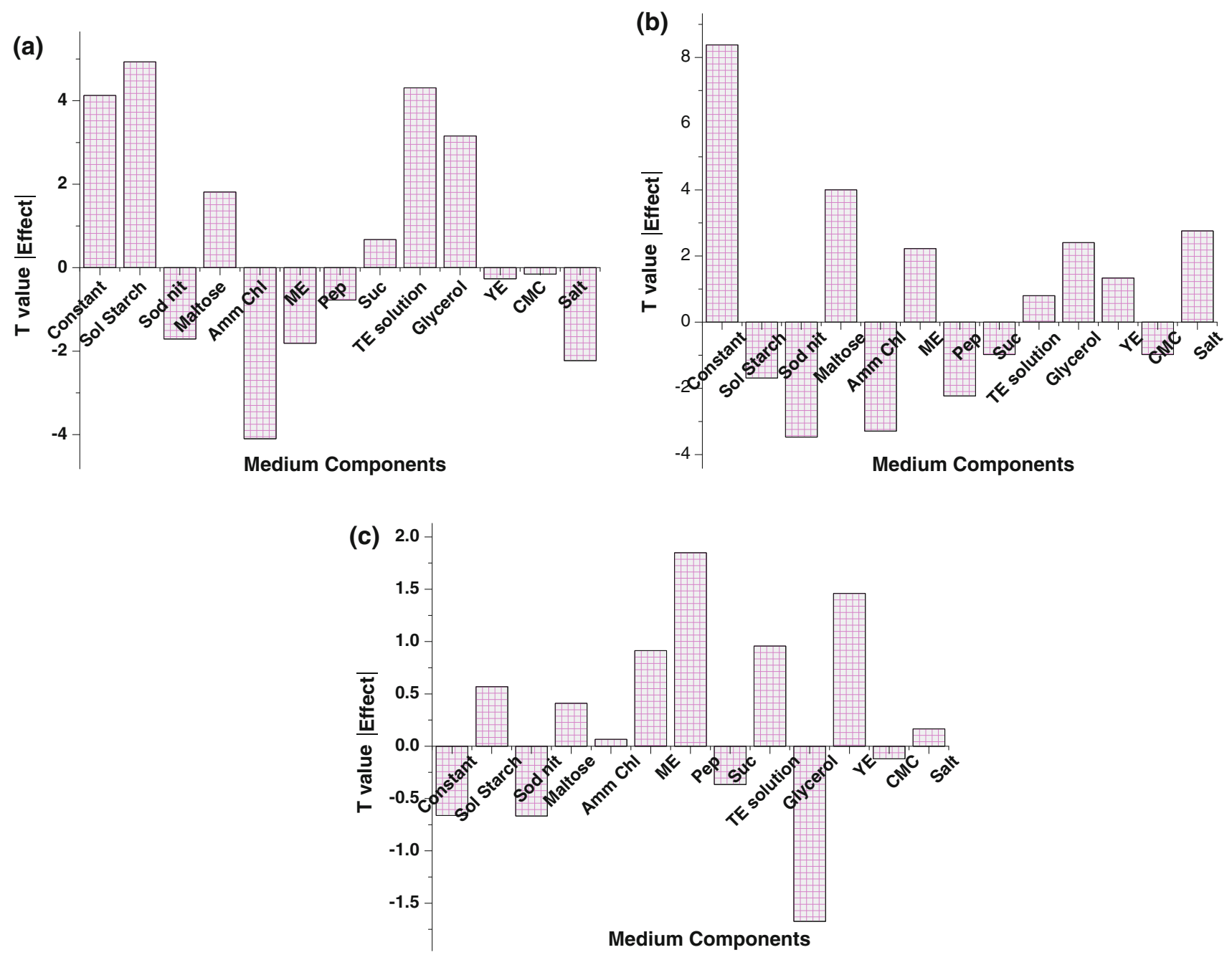

Fig. 1 Pareto plots depicting the main effect of the variables on $\mathbf{a} \alpha$-amylase activity, $\mathbf{b}$ protease activity and $\mathbf{c}$ biomass

Table 2 Regression coefficient results from the data of central composite designed experiments for $\alpha$-amylase activity and protease activity

$p$ value $<0.05$ is significant

\begin{tabular}{|c|c|c|c|c|c|}
\hline \multirow[t]{2}{*}{ Sl. no. } & \multirow[t]{2}{*}{ Components } & \multicolumn{2}{|c|}{$\alpha$-Amylase activity } & \multicolumn{2}{|c|}{ Protease activity } \\
\hline & & $t$ stat & $p$ value & $t$ stat & $p$ value \\
\hline 1 & Constant & 4.1280 & 0.0258 & 8.3769 & 0.0036 \\
\hline 2 & Soluble starch & 4.9329 & 0.0160 & -1.6904 & 0.1895 \\
\hline 3 & Sodium nitrate & -1.7097 & 0.1859 & -3.4698 & 0.0404 \\
\hline 4 & Maltose & 1.8143 & 0.1673 & 4.0036 & 0.0279 \\
\hline 5 & Ammonium chloride & -4.1014 & 0.0262 & -3.2919 & 0.0460 \\
\hline 6 & Malt extract & -1.8143 & 0.1673 & 2.2242 & 0.1126 \\
\hline 7 & Peptone & -0.7736 & 0.4956 & -2.2242 & 0.1126 \\
\hline 8 & Sucrose & 0.6745 & 0.5483 & -0.9787 & 0.3999 \\
\hline 9 & TE solution & 4.3088 & 0.0230 & 0.8007 & 0.4818 \\
\hline 10 & Glycerol & 3.1596 & 0.0509 & 2.4022 & 0.0957 \\
\hline 11 & Yeast extract & -0.2635 & 0.8093 & 1.3345 & 0.2743 \\
\hline 12 & $\mathrm{CMC}$ & -0.1532 & 0.8880 & -0.9787 & 0.3999 \\
\hline 13 & Salt solution & -2.2273 & 0.1123 & 2.7581 & 0.0703 \\
\hline
\end{tabular}



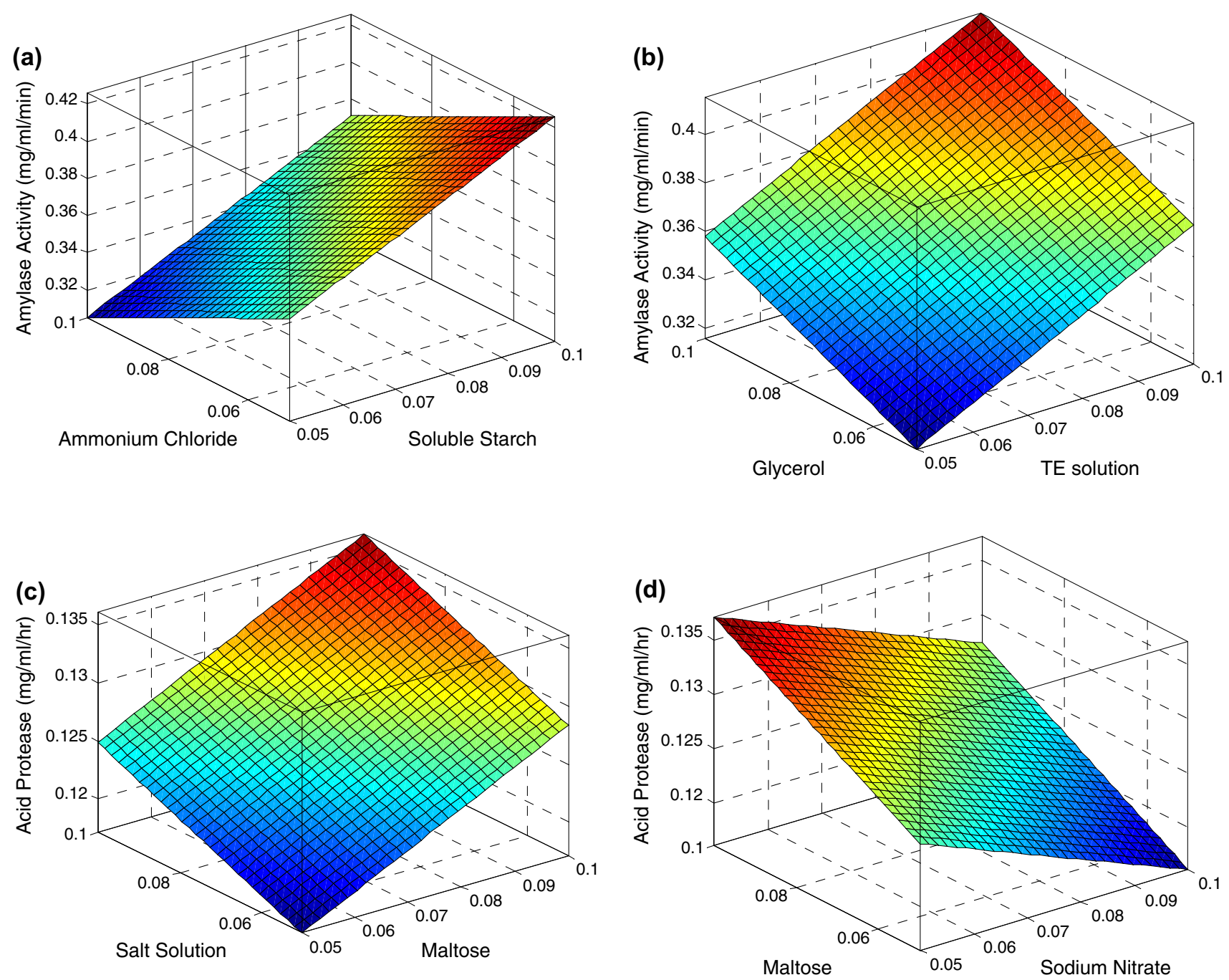

Fig. 2 3D response plots showing the effects of independent variables on $\alpha$-amylase and protease activity

\section{Protease activity}

The effect of sodium nitrate, maltose and $20 \times$ salt solution were found to be more significant than those of other variables for the production of protease enzyme is as evident from the Table 2. Figure $2 \mathrm{c}$, $\mathrm{d}$ represents the response surface plots of the effect of combinations of independent variables such as (1) maltose and sodium nitrate (2) salt solution and maltose for the production of protease enzyme. The interactions of maltose and sodium nitrate on protease production were significant as shown in Fig. 2c. With the increase in concentration of maltose, the activity increased where as the activity decreased with increase in concentration of sodium nitrate. The maximum value observed was $0.136 \mathrm{mg}^{-1} \mathrm{ml}^{-1} \mathrm{~h}^{-1}$ at $0.1 \%$ (w/v) of maltose and $0.05 \%(\mathrm{w} / \mathrm{v})$ of sodium nitrate. The interactions of salt solution and maltose gave the highest activity of $0.135 \mathrm{mg}^{-1} \mathrm{ml}^{-1} \mathrm{~h}^{-1}$ at $0.1 \%$ (w/v) of salt solution and $0.1 \%(w / v)$ of maltose (Fig. 2d).

Biomass

The linear effects of peptone, glycerol and yeast extract for biomass were found to be moderately significant. The biomass varied significantly with the concentration of glycerol, peptone and achieved the maximum biomass of $12 \mathrm{~g} \mathrm{l}^{-1}$ at $0.1 \%(\mathrm{w} / \mathrm{v})$ of peptone and $0.05 \%(\mathrm{w} / \mathrm{v})$ of glycerol.

\section{Discussion}

Kumar et al. (2012) have reported that the increase in concentration of soluble starch increased the production of 
$\alpha$-amylase by $P$. indica. Starch is a preferable carbon source over glucose and its concentration has a direct effect on $\alpha$-amylase production as reported by Gangadharan et al. (2006) and Tanyildizi et al. (2006). Babu and Satyanarayana (1993) and Narang and Satyanarayana (2001) reported that the organic nitrogen sources produce high $\alpha$ amylase yield compared to inorganic nitrogen sources. This is in accordance with our results that describe positive impact of soluble starch and negative impact of inorganic nitrogen sources on $\alpha$-amylase activity.

Carbon sources such as glucose, sucrose, maltose, etc., have a positive influence on the production of protease and also salts such as $\mathrm{KH}_{2} \mathrm{PO}_{4}, \mathrm{MgSO}_{4} \cdot 7 \mathrm{H}_{2} \mathrm{O}$ and $\mathrm{KCl}$ have positive impact on protease production as reported by Kezia et al. 2011. Present study is in concordance with Luciana and Sato (2009) who reported that concentration of $\mathrm{KH}_{2} \mathrm{PO}_{4}$ plays an important role in production of proteolytic enzymes.

Carbon sources play a major role in growth of the microorganisms and also in obtaining high biomass. Present findings reveal that glycerol as a carbon source (economical source) and peptone as a nitrogen source promotes the cell growth and also yield, higher biomass which are in accordance with the earlier reports by Meinicke et al. (2012); Sreekumar and Soundarajan (2010).

The novelty of present paper lies in the screening of medium components to obtain higher enzyme activity and biomass of $P$. indica, which has tremendous applications in the field of plant biotechnology as a biological hardening tool, biofertilizer and biocontrol agent.

\section{Conclusion}

The Plackett-Burman design based on the first order model to screen and evaluate the important medium components greatly influenced the production of $\alpha$-amylase, protease and also biomass. $\alpha$-Amylase, protease and biomass were found to vary from 0.25 to $0.45 \mathrm{mg}^{-1} \mathrm{ml}^{-1} \mathrm{~min}^{-1}, 0.1$ to $0.15 \mathrm{mg}^{-1} \mathrm{ml}^{-1} \mathrm{~h}^{-1}$ and 0.8 to $22.6 \mathrm{~g} \mathrm{l}^{-1}$, respectively, in 16 runs which showed the strong influence of the medium components. Soluble starch, ammonium chloride, TE solution and glycerol were found to be significant for $\alpha$ amylase activity. Sodium nitrate, ammonium chloride, maltose and salt solution were found to be significant for protease activity. Peptone and glycerol supported well the production of high biomass.

Acknowledgments The authors wish to acknowledge Dean of Research and Jain University, Bangalore, for carrying out this work successfully.

Conflict of interest The authors declare that they have no conflict of interest.
Open Access This article is distributed under the terms of the Creative Commons Attribution License which permits any use, distribution, and reproduction in any medium, provided the original author(s) and the source are credited.

\section{References}

Babu KR, Satyanarayana T (1993) Parametric optimization of extracellular $\alpha$-amylase production by thermophilic Bacillus coagulans. Folia Microbiol 38:77-80

Gangadharan D, Sivaramakrishnan S, Namboothiri KM, Pandey A (2006) Solid culturing of Bacillus amyloliquefaciens for $\alpha$ amylase Production. Food Technol Biotechnol 44(2):269-274

Kezia D, Swarnalath G, Dinesh Yadav V, Naidu SV, Narasimha Rao M (2011) Screening of nutritional components for alkaline protease production in submerged fermentation by Bacillus subtilis DKMNR using Plackett-Burman design. Res J Pharm Biol Chem Sci 2(3):598-606

Kumar V, Sahai V, Bisaria VS (2011) High-density spore production of Piriformospora indica, a plant growth-promoting endophyte, by optimization of nutritional and cultural parameters. Bioresour Technol 102:3169-3175

Kumar V, Sahai V, Bisaria VS (2012) Production of amylase and Chlamydospores by Piriformospora indica, a root endophytic fungus. Biocatal Agric Biotechnol 1:124-128

Lowry OH, Rosebrough NJ, Farr AL, Randall RJ (1951) Protein measurement by Folin phenol reagent. J Biol Chem 193:265-275

Luciana FS, Sato HH (2009) Production of alkaline protease from Cellulosimicrobium cellulans. Braz J Microbiol 40(1):54-60

Meinicke RM, Vendruscolo F, Moritz DE, de Oliveira D, Schmidell W, Samohy RW, Ninow JL (2012) Potential use of glycerol as substrate for the production of red pigments by Monascus ruber in submerged fermentation. Biocatal Agric Biotechnol $1: 238-242$

Miller GL (1959) Use of dinitrosalicylic acid reagent for determination of reducing sugar. Anal Chem 31:426-428

Narang S, Satyanarayana T (2001) Thermostable $\alpha$-amylase production by an extreme thermophile Bacillus thermooleovorans. Lett Appl Microbiol 32:31-35

Rai M, Acharya D, Singh A, Varma A (2001) Positive growth responses of the medicinal plants Spilanthes calva and Withania somnifera to inoculation by Piriformospora indica in a field trial. Mycorrhiza 11:123-128

Rajendran A, Thirugnanam M, Thangavelu V (2007) Statistical evaluation of medium components by Plackett-Burman experimental design and kinetic modeling of lipase production by Pseudomonas fluorescens. Indian J Biotechnol 6:469-478

Rodarte MP, Dias DR, Vilela DM, Schwan RF (2011) Proteolytic activities of bacteria, yeasts and filamentous fungi isolated from coffee fruit (Coffea arabica L). Acta Sci Agron 33(3):457-464

Saxena R, Singh R (2010) Statistical optimization of conditions for protease production from Bacillus sp. Acta Biol Szeged 54(2):135-141

Seraman S, Rajendran A, Thangavelu V (2010) Statistical optimization of anticholesterolemic drug lovastatin production by the red mold Monascus purpureus. Food Bioprod Process 88:266-276

Sreekumar G, Soundarajan K (2010) Isolation and characterization of probiotic Bacillus subtilis SK09 from dairy effluent. Indian J Sci Technol 3:863-866

Sumrin A, Ahmad W, Ijaz B, Sarwar MT, Gull S, Kausar H, Shahid I, Jahan S, Asad S, Hussain M, Riazuddin S (2011) Purification and medium optimization of $\alpha$-amylase from Bacillus subtilis 168. Afr J Biotechnol 10(11):2119-2129 
Tanyildizi MS, Elibol M, Ozer D (2006) Optimization of growth medium for the production of á-amylase from Bacillus amyloliquefaciens using response surface methodology. J Chem Technol Biotechnol 81:618-622

Varma S, Varma A, Rexer KH, Hassel A, Kost G, Sarabhoy A, Bisen P, Beutehorn B, Franken P (1998) Piriformospora indica, gen. et sp. nov., a new root-colonizing fungus. Mycologia 90:896-903
Waller F, Mukherjee K, Deshmukh SD, Achatz B, Sharma M, Schäfer P, Kogel KH (2008) Systemic and local modulation of plant responses by Piriformospora indica and related Sebacinales species. J Plant Physiol 165:60-70 